\title{
Nonspecific food dependant exercise-induced anaphylaxis with seizure: a case report
}

\section{Ummer Karadan', Robin George Manappallil2, Ivin Panakkel Zacharia ${ }^{3}$, Thushara Anand ${ }^{4}$}

${ }^{1}$ Senior Consultant and Interventional Neurologist, ${ }^{3}$ Resident, Department of Neurology, Baby Memorial Hospital, Calicut, Kerala, India, ${ }^{2}$ Consultant, ${ }^{4}$ Resident, Department of Internal Medicine, Baby Memorial Hospital, Calicut, Kerala, India

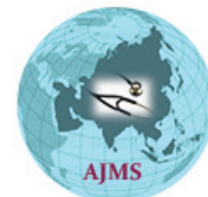

\section{A B S T R A C T}

Exercise has been associated with several systemic reactions. These reactions can vary from mild symptoms to life threatening situations like anaphylaxis. In many of these cases, a predisposing factor in the form of food has been noticed. People may develop anaphylaxis on exercising after consumption of a nonspecific or specific food item. The patient being described developed anaphylaxis with seizure on exercising after having his meal. Nonspecific food dependant exercise-induced anaphylaxis is a rare scenario. Proper history taking is essential, as it can be lifesaving.

Key words: Nonspecific food dependant exercise-induced anaphylaxis; Exercise induced Anaphylaxis; Anaphylaxis; Seizure; Exercise

\section{Access this article online}

Website:

http://nepjol.info/index.php/AJMS DOI: $10.3126 /$ ajms.v11i4.28927

E-ISSN: 2091-0576

P-ISSN: $2467-9100$

Copyright (c) 2020 Asian Journal of Medical Sciences

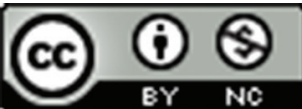

This work is licensed under a Creative Commons Attribution-NonCommercial 4.0 International License.

\section{INTRODUCTION}

Exercise-induced anaphylaxis (EIA) is a rare and potentially life-threatening condition. The symptoms and signs can develop during or shortly after exercise. They include fatigue, pruritus, flushing and urticarial rash, and may progress to anaphylactic shock including bronchospasm or circulatory collapse. In some cases, food intake prior to exercise can trigger the anaphylaxis. EIA associated with any food item is called nonspecific food dependant exercise-induced anaphylaxis (NFDEIA), while that associated with a specific food is termed as food dependent EIA (FDEIA). These reactions occur only when the patient exercises within 2 to 4 hours of food intake. ${ }^{1}$ Hence, unlike the usual EIA, both food intake and exercise are required to trigger off the anaphylaxis. The condition is often underdiagnosed and requires proper history taking for diagnosis. The patient being described is a case of NFDEIA.

\section{CASE PRESENTATION}

A 42 year old male was brought to the emergency department with complaints of 1 episode of generalized tonic clonic seizure after doing treadmill at the gym (airconditioned). The episode lasted less than a minute and was associated with frothing from mouth with no tongue bite. There was no bowel or bladder incontinence. He did not have any seizure, or food or drug allergies in the past. He did not have any comorbidity and was not on any regular medications. He did not take any drugs or alcohol in the last 2 weeks. There was no history of atopy in the family.

On presentation, he was conscious and in postictal state. His pulse was 110/ minute, blood pressure $90 / 60 \mathrm{mmHg}$ and respiratory rate $26 /$ minute with saturation $92 \%$ (in room air). Urticarial rash was seen all over the body. He had 
rhonchi in bilateral lung fields. Other systemic examinations were normal. There were no signs of meningeal irritation. He was given subcutaneous epinephrine ( $0.5 \mathrm{ml}$ of 1:1000), intravenous hydrocortisone $(100 \mathrm{mg})$, intramuscular pheniramine maleate $(45.5 \mathrm{mg})$, intravenous fosphenytoin (loading dose of $20 \mathrm{mg} / \mathrm{kg}$ ), salbutamol $(2.5 \mathrm{mg})$ and fluticasone $(0.5 \mathrm{mg})$ nebulization and normal saline (2 liters); following which he got stabilized. His complete blood counts showed mild leucocytosis (11300 cells/ cumm with neutrophils $75 \%$, lymphocytes $20 \%$, eosinophils $5 \%$ ) with normal haemoglobin and platelets. Other investigations like renal and liver functions, electrolytes, calcium, magnesium, random blood glucose, $\mathrm{HbA1c}, \mathrm{C} 3$ and $\mathrm{C} 4$ complement levels, serum $\operatorname{IgE}$ and urine routine were normal. His electrocardiogram showed sinus tachycardia. Magnetic resonance imaging (MRI) of brain, electroencephalogram (EEG), chest Xray, echocardiography and Holter monitoring test were normal.

On detailed history, he usually has his evening snacks (chicken hotdog and vanilla protein milkshake) after working out in the gym. This routine has been followed for the past 8 months. However, this time he had his routine snack about 1 hour prior to his gym workout. There was no change in the brands of food items. While doing his treadmill, he felt itching sensation all over his body and also noticed erythematous rash. After a minute, he started feeling lightheaded and dyspnoeic, and collapsed. This was followed by generalized tonic clonic seizures. Though there were no seizures in the past, but the patient remembers 2 episodes of urticarial rash when he was working out in the gym after his meals. And during these episodes he had taken oral pheniramine maleate $(25 \mathrm{mg})$ as over the counter medication, and improved. On the basis of his history, the possibility of NFDEIA was considered. Skin prick tests produced reactions to dust, pollens, pineapple, walnut, hazelnut and peanut, and nothing towards meat, milk or vanilla. Supervised graded oral challenges, in a modified way, were done with chicken hotdog and vanilla protein milkshake. He did not have any problem on eating these foods at rest or 6 hours prior to treadmill exercise or 2 hours after treadmill exercise. He was also asymptomatic on exercising in empty stomach. In fear of seizure, he was not willing to do exercise 1 hour after having food. Though treatment of single episode idiopathic seizure (in the absence of abnormal MRI brain, EEG, family history, status epilepticus) is controversial, he was discharged on oral phenytoin $(4 \mathrm{mg} / \mathrm{kg}$ in divided doses) for 1 month in view of his regular driving lifestyle, along with oral levocetrizine ( $5 \mathrm{mg}$ once daily) for 5 days. He was also advised to carrying an epinephrine auto-injector in case of emergency and to avoid physical exercise for at least 4 hours after having food. He was asked to refrain from driving till he is seizure free for 3 months. On review after
1 month, he did not have any allergic reactions or seizures; and phenytoin was tapered and stopped. On 1 year follow up, he did not have any similar episodes.

\section{DISCUSSION}

The first case of EIA was reported by Maulitz et al. in 1979, which was triggered by the intake of shellfish prior to exercise. ${ }^{2}$ In EIA, exercise alone can trigger the allergic reaction. In the case of NFDEIA, the consumption of any food followed by exercise within a few minutes to hours can cause anaphylaxis, while in FDEIA the intake of a specific food is required prior to exercise. Majority of patients would have exercised for years before experiencing their first episode of anaphylaxis.

In both EIA and FDEIA, histamine release following mast cell degranulation plays a major role in pathophysiology. However, the specific events responsible for mast cell activation are unknown. The other proposed mechanisms include exercise-induced changes in blood flow, antigen presentation, blood $\mathrm{pH}$, and increase in gut permeability. ${ }^{3-5}$ Exercise usually increases the levels of serum catecholamines, norepinephrine, and epinephrine. Epinephrine, in high doses, may have a vasodepressor effect. A few other theories have been proposed with respect to FDEIA. One is the activation of tissue transglutaminase, an intestinal enzyme, during exercise. This enzyme is capable of binding and aggregating gliadin moieties to form large immunogenic complexes. ${ }^{6}$ A second theory suggested an increase in the entry of intact or incompletely digested allergens into the circulation due to increased gastric permeability during exercise. And this scenario does not occur at rest. ${ }^{7}$ Another suggestion was the redistribution of blood to the skin and musculature from the viscera during exercise. As a result, the food allergens get transported to the tissues containing mast cells, leading to an allergic reaction. ${ }^{5} \mathrm{~A}$ fourth proposal was that during exercise there is mobilization and activation of immune cells from gut-associated depots. This will lead to stimulation of pro-inflammatory responses. ${ }^{8}$

The Gold standard method for the diagnosis of FDEIA is a 3 day oral challenge test. ${ }^{9}$ The diagnostic criteria which was used in a retrospective study from Sri Lanka are $2,3,10,11$

- World Allergy Organization (WAO) outlined criteria for clinical diagnosis of anaphylaxis ${ }^{10}$

- The onset of symptoms occurred on exertion within 4 hours of ingesting the implicated food

- The ability to eat the implicated food independent of exercise, or ability to exercise safely if the food was not taken in the preceding 4 hours 
- Evidence of sensitivity to the food by in vitro (ImmunoCap serum IgE levels to the specific food) or in vivo (skin prick test).

The mechanism of anaphylaxis in NFDEIA is unclear. The vasolability that occurs during exercise gets amplified when a meal precedes it. It has been demonstrated that there is shift of more than $85 \%$ cardiac output to the skeletal muscles during heavy physical exercise. And a part of this shift is compensated by a transfer of about $23 \%$ of splanchnic blood from the resting state. Ingestion of food can interfere with this compensatory mechanism and could enhance the tendency for orthostatic hypotension which is usually seen after exercise. Drugs like NSAIDs and aspirin, dust, pollen, hot and humid climate, stress and menses can act as contributing factors. ${ }^{7,12,13}$

The management of NFDEIA and FDEIA is mainly by prevention of such anaphylactic attacks by avoiding physical exertion for at least 4 hours following intake of food. Other measures include avoiding exercise in extreme weathers such as hot and humid or cold temperatures, decreasing the intensity of exercise and carrying an epinephrine auto-injector during exercise. ${ }^{14}$ The treatment involves routine anaphylaxis medications like epinephrine, hydrocortisone, antihistamine and bronchodilators. Taking antihistamines or $\mathrm{H} 2$ blockers, as prophylaxis, prior to exercise is controversial. ${ }^{3,15}$ In cases of refractory FDEIA, omalizumab, a recombinant DNA monoclonal antibody which binds to $\operatorname{IgE}$ and neutralises its activity in type I allergic reactions, has been tried successfully as prophylaxis. ${ }^{16}$ The administration of misoprostol, a prostaglandin E1 analogue, prior to exercise has shown to decrease wheat-dependent anaphylaxis, probably by an upregulation of gastrointestinal breakdown of allergic particles. ${ }^{17}$

The occurrence of seizure in anaphylaxis is uncommon. Brain hypoxia resulting from anaphylaxis associated hypotension is believed to be the main mechanism. ${ }^{18,19}$ Another possibility is the disruption of the blood-brain barrier by pro-inflammatory cytokines leading to the spread of peripheral inflammatory response to the brain. ${ }^{20}$ The activation of mast cells in the brain can disrupt the blood brain barrier, leading to local neuronal inflammation which can act as an epileptogenic focus. ${ }^{21}$ Moreover, Fc-epsilon receptors have also been identified on neurons, raising the possibility of a direct attack by the allergic triggers through the disrupted blood brain barrier, and thereby allowing a secondary entry of immunoglobulins. ${ }^{22}$

Our patient developed anaphylactic seizure when he exercised after taking a meal 1 hour prior to it. He did not have any allergies to the food he had taken. He also did not have anaphylaxis when he exercised without a prior meal. This raised the diagnosis of NFDEIA. The pathogenesis in this case is from mechanical factors rather than immunologic. To the best of our knowledge, NFDEIA presenting with seizure is an unreported scenario.

\section{CONCLUSION}

With less than a handful of cases being reported, NFDEIA is a rare condition, probably because of lack of awareness. These patients present with unexplained allergic reactions and get routine anaphylaxis treatment. A proper history is required to establish the diagnosis. These patients should be advised to avoid exercise for at least 4 hours following a meal in order to prevent life threatening allergic reactions.

\section{REFERENCES}

1. Sampson HA, Burks AW. Adverse reactions to foods. In: Adkinson NF, Yunginger JW, Buss WW, editors. Middleton's Allergy: Principles and Practice. 7th ed. Maryland Heights: Mosby; 2008. p. 1156.

2. Maulitz RM, Pratt DS and Schocket AL. Exercise-induced anaphylactic reaction to shellfish. J Allergy Clin Immunol. 1979; 63:433-434.

https://doi.org/10.1016/0091-6749(79)90218-5

3. Barg W, Medrala W and Wolanczyk-Medrala A. ExerciseInduced Anaphylaxis: An Update on Diagnosis and Treatment. Curr Allergy Asthma Rep. 2011; 11:45-51.

https://doi.org/10.1007/s11882-010-0150-y

4. Sheffer AL, Tong AKF and Murphy GF. Exercise-induced anaphylaxis: a serious form of physical allergy associated with mast cell degranulation. Journal of Allergy and Clinical Immunology. 1985;75(4):479-484.

https://doi.org/10.1016/S0091-6749(85)80021-X

5. Robson-Ansley $P$ and Toit GD. Pathophysiology, diagnosis and management of exercise-induced anaphylaxis. Current Opinion in Allergy and Clinical Immunology. 2010;10(4):312-317.

https://doi.org/10.1097/ACl.0b013e32833b9bb0

6. Palosuo K, Varjonen E, Kekki OM, Klemola T, Kalkkinen N, Alenius $\mathrm{H}$, et al. Wheat omega-5 gliadin is a major allergen in children with immediate allergy to ingested wheat. J Allergy Clin Immunol 2001;108:634-638.

https://doi.org/10.1067/mai.2001.118602

7. Matsuo H, Morimoto K, Akaki T, Kaneko S, Kusatake K, Kuroda T, et al. Exercise and aspirin increase levels of circulating gliadin peptides in patients with wheat-dependent exercise-induced anaphylaxis. Clin Exp Allergy 2005; 35:461-466.

https://doi.org/10.1111/j.1365-2222.2005.02213.x

8. Cooper DM, Radom-Aizik S, Schwindt C, Zaldivar F Jr. Dangerous exercise: Lessons learned from dysregulated inflammatory responses to physical activity. J Appl Physiol 2007; 103:700-709.

https://doi.org/10.1152/japplphysiol.00225.2007

9. Pacharn $P$, Jirapongsananuruk $O$, Daengsuwan T, Vichyanond $P$, Visitsunthorn N. Wheat-dependent, exercise-induced anaphylaxis in Thai children: a report of 5 cases. Asian Pac J Allergy Immunol 2009;27:115-120 
10. Muraro A, Roberts G, Worm M, Bil MB, Brockow K, Fernández Rivas M, et al. Anaphylaxis: guidelines from the European Academy of Allergy and Clinical Immunology. Allergy 2014;69:1026-1045. https://doi.org/10.1111/all.12437

11. de Silva NR, Dasanayake WM, Karunatilleke C and Malavige GN. Food dependant exercise induced anaphylaxis a retrospective study from 2 allergy clinics in Colombo, Sri Lanka. Allergy Asthma Clin Immunol. 2015; 11(1):22. https://doi.org/10.1186/s13223-015-0089-6

12. Shadick NA, Liang MH, Partridge AJ, Bingham C, Wright E, Fossel $\mathrm{AH}$, et al. The natural history of exercise-induced anaphylaxis: Survey results from a 10-year follow-up study. J Allergy Clin Immunol 1999; 104:123-127. https://doi.org/10.1016/S0091-6749(99)70123-5

13. Bito $T$, Kanda E, Tanaka M, Fukunaga A, Horikawa $T$ and Nishigori C. Cow's milk-dependent exercise-induced anaphylaxis under the condition of a premenstrual or ovulatory phase following skin sensitization. Allergol Int 2008; 57:437-439. https://doi.org/10.2332/allergolint.C-08-62

14. Soyer OU and Sekerel BE. Food dependent exercise induced anaphylaxis or exercise induced anaphylaxis? Allergol Immunopathol (Madr) 2008; 36(4):242-243. https://doi.org/10.1157/13127050

15. Castells MC, Horan RF and Sheffer AL. Exercise induced anaphylaxis. Curr Allergy Asthma Rep 2003; 3(1):15-21. https://doi.org/10.1007/s11882-003-0005-x

16. Bray SM, Fajit ML and Petrov AA. Successful treatment of exercise-induced anaphylaxis with omalizumab. Ann Allergy Asthma Immunol 2012; 109(4):281-282. https://doi.org/10.1016/j.anai.2012.07.021

17. Takahashi A, Nakajima K, Ikeda M, Sano S, Kohno K and Morita E. Pre-treatment with misoprostol prevents fooddependent exercise-induced anaphylaxis (FDEIA). Int J Dermatol 2011; 50(2):237-238. https://doi.org/10.1111/j.1365-4632.2010.04314.x

18. Akın O, Yavuz ST, Hacıhamdioğlu B, Sarı E, Gürsel $O$ and Yeşilkaya E. Anaphylaxis to gonadorelin acetate in a girl with central precocious puberty. J Pediatr Endocrinol Metab. 2015; 28:1387-1389

https://doi.org/10.1515/jpem-2015-0183

19. Osman BM, Maga JM and Baquero SM. Case report: management of differential diagnosis and treatment of severe anaphylaxis in the setting of spinal anesthesia. J Clin Anesth. 2016; 35:145-149. https://doi.org/10.1016/j.jclinane.2016.07.009

20. Falsaperla R, Pavone P, Miceli Sopo S, Mahmood F, Scalia F, Corsello $\mathrm{G}$, et al. Epileptic seizures as a manifestation of cow's milk allergy: a studied relationship and description of our pediatric experience. Expert Rev Clin Immunol. 2014; 10:1597-1609. https://doi.org/10.1586/1744666X.2014.977259

21. Theoharides TC, Zhang B. Neuro-inflammation, blood-brain barrier, seizures and autism. J Neuroinflammation. 2011; 8:168. https://doi.org/10.1186/1742-2094-8-168

22. van der Kleij $\mathrm{H}$, Charles $\mathrm{N}$, Karimi K, Mao YK, Foster J, Janssen L, et al. Evidence for neuronal expression of functional Fc (epsilon and gamma) receptors. J Allergy Clin Immunol. 2010; 125:757-760.

https://doi.org/10.1016/j.jaci.2009.10.054

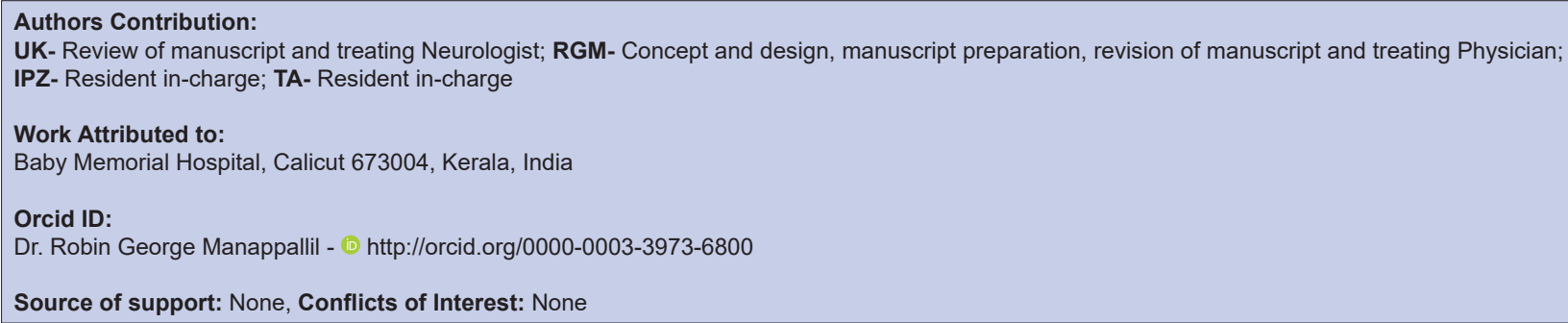

